\title{
Laparoscopic Resection of Presacral Tumor: A New Approach in the Era of the Minimally Invasive Surgery
}

\author{
Chang Woo Kim, M.D., Suk-Hwan Lee, M.D. \\ Department of Surgery, Kyung Hee University Hospital at Gangdong, Kyung Hee University School of Medicine, Seoul, Korea
}

\begin{abstract}
Presacral tumors are rare; however, once diagnosed, surgical resection is recommended even in asymptomatic patients as there is potential risk for growth or malignant transformation. Many different types of surgical approaches to resect presacral tumors have been reported including posterior, anterior, and combined abdominosacral approaches. With introduction of the minimally invasive approach, laparoscopic or robotic approaches to resect presacral tumors are reported increasingly. We report a case of successful anterior laparoscopic resection for a presacral mass that was incidentally diagnosed during management of pancreatitis.
\end{abstract}

Keywords: Laparoscopy, Presacral tumor, Tailgut cyst

Supplementary video file: This article contains supplementary material (https://doi.org/10.7602/ jmis.2019.22.3.131).
Received August 23, 2019

Revised September 4, 2019

Accepted September 6, 2019

Corresponding author

Suk-Hwan Lee

Department of Surgery, Kyung Hee University Hospital at Gangdong,

Kyung Hee University School

of Medicine, 892 Dongnam-ro,

Gangdong-gu, Seoul 05278, Korea

Tel: +82-2-440-6134

Fax: +82-2-440-6073

E-mail: leeshdr@khu.ac.kr

ORCID:

https://orcid.org/0000-0001-6470-8620

Copyright @ 2019 The Journal of Minimally Invasive Surgery. All rights reserved.

\section{INTRODUCTION}

Presacral tumor is rare, and most reported series are case reports. Many different kinds of tumors can occur as this area harbors varieties of embryologic remnant tissues and various tissue types. Presacral tumors are subdivided by 5 categories based on origin, i.e., congenital, inflammatory, neurogenic, osseous, and miscellaneous tumors., ${ }^{1,2}$ Both benign and malignant tumor can occur. Solid lesions on magnetic resonance imaging (MRI) suggest malignant characteristics. ${ }^{3}$ Most tumors are diagnosed incidentally and do not cause specific symptoms. Surgical resection is recommended upon diagnosis, even in asymptomatic patients, as there is potential risk for growth or malignant transformation. ${ }^{4,5}$

Many different types of surgical approaches to resect pre- sacral tumors are reported. Posterior, anterior, combined abdominosacral approaches are commonly performed, but transvaginal or transrectal approaches are also performed to resect presacral tumors. With introduction of the minimally invasive approach, laparoscopic or robotic approaches to resect presacral tumors are reported increasingly. Herein, we reported a case of presacral mass incidentally diagnosed during management of pancreatitis and that was successfully resected with an anterior laparoscopic approach.

\section{OPERATIVE PROCEDURES}

A 55-year-old male patient was admitted with acute pancreatitis. During the follow-up examination of his pancreatitis, a huge pelvic mass was found incidentally. It occupied 
the whole pelvic cavity, pushing the low rectum to the right side. The patient denied any obstructed symptoms of defecation. Pelvic MRI confirmed that the mass measuring 7.6×6.1 $\mathrm{cm}$ was more likely an epidermoid or tailgut cyst rather than a malignant tumor. The presacral tumor was successfully resected via the anterior laparoscopic approach.

The rectum and mesorectum were preserved during medial dissection. Presacral venous plexus was preserved at the posterior part. Lastly, we avoided injury to the ureter and autonomic nerve for the lateral side. During the dissection of the huge presacral tumor, distal dissection was most complicated because the tumor itself prohibited the proper visualization of the dissection plane. Careful traction with counter traction of the surgical plane is an essential prerequisite for the successful bloodless dissection. The specimen was extracted through the right lower quadrant trocar site after extending incision about $2.5 \mathrm{~cm}$.

We completed laparoscopic resection without any events, and pathology confirmed the diagnosis of tailgut cyst. The patient was discharged to home at postoperative day five without any complications.

\section{DISCUSSION}

The posterior approach or Kraske trans-sacral approach was a classic approach and provided good surgical access with a short route of entry to the presacral space. ${ }^{1}$ Division of pelvic floor muscle and coccygectomy or sacrectomy produced postoperative pain and possibilities of fecal incontinence. An abdominosacral approach is recommended for large tumors extending upward as high as the sacral promontory and downward as low as S4. The anterior approach or abdominal approach is indicated for tumors with the lowest margin located above S4 in the absence of nerve involvement. This approach provided excellent exposure of pelvic structures such as iliac vessels, ureter, and pelvic autonomic nerves. Usually, an anterior approach requires a long midline incision; however, with the introduction of minimally invasive approaches, presacral tumors are resected with anterior laparoscopic, ${ }^{6-12}$ posterior endoscopic, ${ }^{6}$ and robotic methods. ${ }^{13-15}$

Complete resection without perforation of presacral tumor is very important since the tumor may harbor malignant tissues. We dissected the presacral tumor without perforation using the anterior laparoscopic approach.

In summary, a laparoscopic anterior approach is feasible and safe to resect a presacral tumor. Care should be taken not to injure any vascular, neurologic, and visceral organ damage nor perforation of the cystic lesion.

\section{ORCID}

Chang Woo Kim, https://orcid.org/0000-0002-6317-8354

Suk-Hwan Lee, https://orcid.org/0000-0001-6470-8620

\section{AUTHORS' CONTRIBUTIONS}

Conceptualization: SHL. Formal analysis: CWK. Methodology: CWK, SHL. Writing-original draft: CWK, SHL. Writing-review and editing: SHL.

\section{CONFLICT OF INTEREST}

None.

\section{FUNDING}

None.

\section{ACKNOWLEDGMENTS}

None.

\section{REFERENCES}

1) Aranda-Narvaez JM, Gonzalez-Sanchez AJ, Montiel-Casado C, et al. Posterior approach (Kraske procedure) for surgical treatment of presacral tumors. World J Gastrointest Surg 2012;4:126-130.

2) Hobson KG, Ghaemmaghami V, Roe JP, Goodnight JE, Khatri VP. Tumors of the retrorectal space. Dis Colon Rectum 2005;48: 1964-1974.

3) Yang DM, Kim HC, Lee HL, Lee SH, Kim GY. Squamous cell carcinoma arising from a presacral epidermoid cyst: CT and MR findings. Abdom Imaging 2008;33:498-500.

4) Simpson PJ, Wise KB, Merchea A, et al. Surgical outcomes in adults with benign and malignant sacrococcygeal teratoma: a single-institution experience of 26 cases. Dis Colon Rectum 2014; 57:851-857.

5) Mathis KL, Dozois EJ, Grewal MS, Metzger P, Larson DW, Devine RM. Malignant risk and surgical outcomes of presacral tailgut cysts. Br J Surg 2010;97:575-579.

6) Nieuwenhuis DH, Gagner M, Consten EC. The endoscopic perineal approach to the presacral space: an excision biopsy. J Laparoendosc Adv Surg Tech A 2009;19:799-801.

7) Lim SW, Huh JW, Kim YJ, Kim HR. Laparoscopy-assisted resection of tailgut cysts: report of a case. Case Rep Gastroenterol 2011; $5: 22-27$.

8) Tobias-Machado M, Hidaka AK, Sato LLK, Silva IN, Mattos PAL, Pompeo ACL. Laparoscopic resection of prescral and obturator fossa schwannoma. Int Braz J Urol 2017;43:566. 
9) Poskus E, Makunaite G, Kubiliute I, Danys D. Case report: Laparoscopic approach in the treatment of presacral lipoma. Ann Med Surg (Lond) 2018;35:64-66.

10) Hove MG, Gil JM, Rodriguez TS, et al. Laparoscopic approach to tailgut cyst (retrorectal cystic hamartoma). J Minim Access Surg 2019;15:262-264.

11) Mohri K, Kamiya T, Hiramatsu K, et al. Laparoscopic surgery of a presacral epidermoid cyst: A case report. Int J Surg Case Rep 2019;59:23-26.

12) Sezgin B, Camuzcuoglu A, Camuzcuoglu H. Laparoscopic Resection of An Extragastrointestinal Stromal Tumor in the Presacral
Area. J Minim Invasive Gynecol 2019;26:812-813.

13) Carchman E, Gorgun E. Robotic-assisted resection of presacral sclerosing epithelioid fibrosarcoma. Tech Coloproctol 2015;19: 177-180.

14) Eftaiha SM, Kochar K, Pai A, Park JJ, Prasad LM, Marecik SJ. Robot-assisted approach to a retrorectal lesion in an obese female. J Vis Surg 2016:2:59.

15) Criss CN, Grant C, Ralls MW, Geiger JD. Robotic resection of recurrent pediatric lipoblastoma. Asian J Endosc Surg 2019;12:128131. 